\title{
Exploration of multidimensional interactive classroom teaching for CCD principle and application course
}

Xinghu Fu, Ailing Tan, Baojun Zhang, Guangwei Fu, Weihong Bi

Xinghu Fu, Ailing Tan, Baojun Zhang, Guangwei Fu, Weihong Bi, "Exploration of multidimensional interactive classroom teaching for CCD principle and application course," Proc. SPIE 10452, 14th Conference on Education and Training in Optics and Photonics: ETOP 2017, 104524L (16 August 2017); doi: $10.1117 / 12.2268527$

Event: 14th Conference on Education and Training in Optics and Photonics, ETOP 2017, 2017, Hangzhou, China 


\title{
Exploration of multidimensional interactive classroom teaching for CCD principle and application course
}

\author{
Xinghu Fu*, Ailing Tan, Baojun Zhang, Guangwei Fu, and Weihong Bi \\ School of Information Science and Engineering, The Key Laboratory for Special Fiber and Fiber \\ Sensor of Hebei Province, Yanshan University, Qinhuangdao 066004, China
}

\begin{abstract}
The CCD principle and application course is professional and comprehensive. It involves many subject contents. The course content includes eight aspects. In order to complete the teaching tasks within a limited time, improve the classroom teaching quality and prompt students master the course content faster and better, so the multidimensional interactive classroom teaching is proposed. In the teaching practice, the interactive relationship between the frontier science, scientific research project, living example and classroom content is researched detailedly. Finally, it has been proved practically that the proposed multidimensional interactive classroom teaching can achieved good teaching effect.
\end{abstract}

Keywords: Multidimensional, interactive, classroom teaching, teaching efficiency

\section{INTRODUCTION}

The CCD (Charge coupled devices) is a semiconductor surface device, which is in the form of charge pocket to storage and delivery of information ${ }^{[1-3]}$. It has the advantage of small size, light weight, low power consumption, low working voltage, high sensitivity and wide dynamic range. So it is widely used in image sensing, signal processing and digital storage $^{[4-5]}$. Willard Boyle and George Smith, which are two American scientists, have won The Nobel Prize for physics in 2009 due to the invention of CCD. The CCD principle and application course is professional and comprehensive ${ }^{[6-7]}$. It involves many subject contents ${ }^{[8]}$, such as optoelectronics, optics, electronics, computer, etc. Therefore, through the study of CCD principle and application course, students who are majoring in optoelectronic information can not only improve the flexibility in the use of disciplines knowledge of optics, optoelectronics, electronics and computer, but also bring up these innovation ability to draw an analogy and inferences about other cases from one instance.

In order to improve the quality of classroom teaching and enable students to master relevant knowledge of $\mathrm{CCD}$ principle and application in the limited 24 class hours, the author who from the teaching objectives, according to the teaching reform and exploration of three years, put some teaching experience on teaching methods and teaching content organization. In order to complete the teaching tasks within a limited time, improve the classroom teaching quality and prompt students master the course content faster and better, so the multidimensional interactive classroom teaching is proposed.

*fuxinghu@ysu.edu.cn;

14th Conference on Education and Training in Optics and Photonics: ETOP 2017, edited by Xu Liu,

Xi-Cheng Zhang, Proc. of SPIE Vol. 10452, 104524L · @ 2017 ICO, IEEE, OSA, SPIE

CCC code: $0277-786 X / 17 / \$ 18 \cdot$ doi: $10.1117 / 12.2268527$ 


\section{TEACHING CONTENT REFORM}

The course content of "CCD principle and application"is a lot, and it includes eight aspects, including the introduction, CCD working principle, performance parameters, driving principle, product introduction, light source, video signal processing and acquisition, application examples. The time allocation of the content is shown in Table 1.

Table 1 The time allocation of the content

\begin{tabular}{|c|c|c|c|}
\hline $\begin{array}{c}\text { Class } \\
\text { number }\end{array}$ & Section & Contents & $\begin{array}{l}\text { Class } \\
\text { hours }\end{array}$ \\
\hline 1 & Introduction & CCD concept, type and application & 2 \\
\hline 2 & $\begin{array}{l}\text { CCD Working } \\
\text { Principle }\end{array}$ & $\begin{array}{c}\text { Charge storage, charge coupling, charge detection, charge } \\
\text { injection, charge coupled imaging devices }\end{array}$ & 2 \\
\hline 3 & $\begin{array}{l}\text { Performance } \\
\text { Parameters }\end{array}$ & $\begin{array}{l}\text { Charge transfer efficiency, photoelectric conversion characteristic, } \\
\text { spectral effect, dynamic range, resolution }\end{array}$ & 2 \\
\hline 4 & Driving Principle & CCD drive principle, $\mathrm{CCD}$ drive circuit & 2 \\
\hline 5 & Product Introduction & Typical CCD chip introduction & 2 \\
\hline 6 & Product Introduction & Special CCD chip introduction & 2 \\
\hline 7 & Light Source & $\begin{array}{l}\text { Natural light source, artificial light source, the basic characteristics } \\
\text { of light source parameters and light source selection }\end{array}$ & 2 \\
\hline 8 & $\begin{array}{l}\text { Video Signal } \\
\text { Processing And } \\
\text { Acquisition }\end{array}$ & Digitalization of CCD Video Signal & 2 \\
\hline 9 & $\begin{array}{l}\text { Video Signal } \\
\text { Processing And } \\
\text { Acquisition }\end{array}$ & $\begin{array}{c}\text { CCD video signal quantization processing, acquisition and } \\
\text { interface }\end{array}$ & 2 \\
\hline 10 & Application Examples & $\begin{array}{l}\text { CCD optical basics, CCD for one-dimensional measurement, } \mathrm{CCD} \\
\text { for rail vibration non-contact measurement }\end{array}$ & 2 \\
\hline 11 & Application Examples & $\begin{array}{l}\text { CCD high-precision filament diameter measurement system, linear } \\
\text { array CCD in the scanning copy of the application, CCD for digital } \\
\text { cameras, etc. }\end{array}$ & 2 \\
\hline 12 & Review & Review & 2 \\
\hline & & Total & 24 \\
\hline
\end{tabular}

In order to complete the teaching task in limited 24 class hours, and enable students to fully master the course content, the author carries out the reform of the teaching content from the following three aspects. In the teaching practice, the interactive relationship between the frontier science, scientific research project, living example and classroom content is 
researched detailedly.

\subsection{Subdivide content, combining classification}

The course covers a wide range of knowledge but costs less hours, so it may be make students produce obscure feeling in the classroom teaching process, and affect the enthusiasm of students. Therefore, in the teaching content arrangement, we from simple to difficult, from the shallower to the deeper, pay more attention to the basic content of teaching and to explain the application of basic knowledge, so as to improve the efficiency of classroom teaching and to fully stimulate students interest in this course. The contents of the course are as follows:

(1) CCD basic characteristics: mainly including CCD definition and classification, performance parameters, working principle.

(2) CCD driving principle: mainly including the CCD working time sequence, the driving circuit, the typical product profile.

(3) CCD applications: including light sources, signal processing and acquisition, typical application example.

The content of the course is divided into three parts, students can know the content of the course at a glance, from whole and detail to understand and master of the basic content of the course. We divides the content of the course into three parts: first of all, learning CCD basic characteristics, then study CCD driving principle, finally learning knowledge of CCD application. The three parts is logical, and it can guide the students study better and better. In the classroom, according to the content of the teaching, the students enthusiasm for learning is high and it is easy to understand and master what they have learned.

\subsection{Prominent key points, fan out from point to area}

It is impossible to do everything that so many courses content of teaching are completed in a limited period of time, we must focus on the distinction between key and difficult points to elaborate. Therefore, in the classroom teaching, we not only pay attention to the basic knowledge of teaching, but also to make clear direction of learning professional knowledge and highlight the key point of the course content. Moreover, we not only pay attention to the representation of knowledge points, but also pay attention to the relevance of knowledge points to fan out from point to area.

When studying the working principle of CCD, it is necessary to show that this chapter is the theoretical basis and key content of this course, the core of which is the charge storage, coupling, injection and detection. The charge transfer of CCD is to guarantee the normal work of the CCD product, and these contents are very important to study the following chapters. The author visually shows the charge coupling process of CCD through the animation, so that students fully understand how the charge is transferred from one electrode to the adjacent electrode.

Focusing on the working time sequence of CCD in the study of the driving principle of CCD. Firstly, using the TCD1206UD line array CCD as an example, introduce it as a image sensor which has high sensitivity, low dark current, double channel two line array. Then, introduce its the pin function of signal transfer, reset, integration and output. Finally, focus on learning transfer gate signal, phase overlap shift pulse, reset pulse, and design its working time sequence according to these signals. In the design of the working time sequence, students also realized the correct working time sequence is the guarantee of the normal driving CCD.

In the classroom, students can be targeted and relaxed degrees, so they can faster grasp the relevant content of the course by clear direction and highlight the focus of teaching.

\subsection{Reasonable choice, highlighting new ideas}

In the classroom teaching process, the author notes that some of the content has been quite old, no longer applied, but there are many new technologies continue to emerge. Therefore, according to the professional characteristics of 
optoelectronics information, keep the classic theory and principle content of teaching materials, make reasonable choice, supplement the contents which reflect the professional characteristics, and further highlight the new ideas of CCD technology.

When teaching the application part of $\mathrm{CCD}$, as for the processing of its signal, to mainly introduce the binaryzation processing of CCD video signal, including the fixed threshold method, floating threshold method, differential method and comparative law. As for collecting of its signal, to mainly introduce the method of the binaryzation acquisition of hardware logic circuit and binaryzation data acquisition of edge delivery number. As for the processing of the quantified of CCD video signal, the related content of sampling, quantification and encoding are mentioned in Communications principles, Signals and systems, and Digital signal processing technology courses, so it can make a brief introduction.

When studying the light source part of the CCD, it should be appropriate to add some new achievements in light sources research at home and abroad in recent years. It can enable students to keep up with development pace of CCD technology and improve the interest in the course of learning. For example, the semiconductor light-emitting diode (LED), which has the advantage is fast luminous response speed, long lifetime, driving simple and good monochromaticity, and are widely used as the light source of CCD camera. The Stanford University scientists used high energy pulsed ultraviolet laser drilling technology to drill 12 350 micron hole in Drosophila head, and use CCD camera to film drilling process and to map out their brain activity. These will focus the attention of students, which can cultivate their innovative ability.

By deleting the old content, adding the new technology and new development content of related major, we not only can make students broaden their horizons, from passive learning to active learning, but also can stimulate the interest in learning and achieve a good teaching effect .

\section{TEACHING METHODS REFORM}

In order to make the teaching more vivid and concrete, make students easier to understand the basic content of the curriculum, the author selected some typical examples which need to be mastered in the classroom, combined with the frontier science, scientific research project, life example to reform and innovate on the teaching method.

\subsection{Combined with Frontier Science}

For the new things in society, students can produce strong interest. In order to fully mobilize the enthusiasm of the students, the author combines the development trend of frontier science, integrates the current hot spot of science news into the classroom teaching and highlights the importance of CCD in Frontier Science.

When teaching LED can be used as a CCD light source, we combine with the hot events of LED wireless communication network at that time. That is, the ordinary LED light bulbs is installed microchips by the researchers of the Fudan University, and the network signal is accessed to a 1W LED light bulb, as a result, under the light of 4 computers can access the Internet, its off-line maximum unidirectional transmission rate reach $3.7 \mathrm{G} / \mathrm{S}$ and create a world record of unidirectional transmission speed in the field of visible light wireless communication. Students have also been inspired to put forward in some place and achieve LED communications, which including train sleeper, aircraft cabin, hotels and so on.

When studying the applications of CCD, combine teaching with the lunar probe satellite, which are launched by our country at that time. That is, the resolution of CCD stereo camera on Chang'E1 is 120 meters, equivalent to only see the size of the parking lot of objects. The resolution of CCD stereo camera on Chang'E2 is 1 meters when it is 15 kilometers 
from the moon, equivalent to see the shape of the car in the parking lot. In the classroom, students are inspired to discuss the application of CCD in future aerospace, this gained good response.

Through the combination of teaching and frontier science, we not only make students appreciate the charm of Frontier Science, but also improve the teaching efficiency of teachers, and cultivate the students ability of independent thinking.

\subsection{Combined with scientific research projects}

Teaching is the foundation of scientific research, and the two are closely related. In the teaching process, what are introduce relevant research projects can truly achieve the organic combination of scientific research and teaching. We also combined with the National Natural Science Foundation of China and the provincial or ministerial level projects which chaired by the Research Group, and incorporate the research content of the project into the classroom teaching of CCD principles and applications.

In the teaching of the working principle of $\mathrm{CCD}$, involving external light injection for photoelectric conversion, the main reason is that the CCD is a photosensitive element. The author also combine with the special light cone in National Natural Science Foundation of China which presided over by him, discuss the influence of CCD light injection in the classroom and it fully stimulate the enthusiasm of students to participate in scientific research.

In the teaching of the performance parameters of $\mathrm{CCD}$, combined with the innovative experiment project of the Research Group--design and manufacture of unmanned intelligent vehicle based on photoelectric navigation to introduce. That is, the surrounding environment information is caught by smart car through CCD. It can automatically achieve the function of move along the runway, turn left and turn right and parking. In the classroom, the related technology of CCD is discussed, it can guide students from passive learning to active learning .

In this way, with the combination of scientific research projects, so that students can keep up with the times and the pace of scientific research, focus attention and get good results.

\subsection{Combined with living examples}

In the teaching process, some knowledge comes from life, but higher than life. Using multimedia technology through a variety of ways to show the specific examples of CCD in life, such as video, audio and animation, to enrich the rational understanding of students, and fully grasp the working principle and the driving principle of CCD key point.

When teaching the typical products of $\mathrm{CCD}$, quoting intelligent mobile phone which widely praised by consumers. Pointed out that up to several million pixels camera function, the using image sensor is generally a CMOS sensor which is complementary metal oxide semiconductor image sensor. The main difference between CCD and CMOS is very power saving, only about $1 / 3$ of ordinary CCD. Moreover, the ultra miniaturization, many features can be integrated on a chip, it has been used for the micro applications, such as security monitoring, video doorbell, video phones and medical devices.

When introducing the special type of $\mathrm{CCD}$, firstly, introducing night vision instrument and sight glass which are based on shimmer CCD and its application in the field of military sniper rifles, telescopes, missile navigation and so on. Secondly, introducing video surveillance, night vision and camera which are based on Infrared CCD and its application in the field of safety and theft prevention, automobile nocturnal, medical diagnosis and so on. Thirdly, introducing transmission photography which are based on X light CCD and its application in the field of medical digital imaging, industrial nondestructive testing, quality inspection and so on. Finally, introducing detector and camera which are based on Ultraviolet CCD and its application in the field of bio-medicine, detection alarm and so on.

In this way, with the combination of life examples, we not only can make the students to enhance the ability to use the knowledge to learn things, but also improve students ability to discover problems, analyze problems and solve problems 
in life. Through three years of teaching practice, the student academic performance distribution is shown in Table 2 .

Table 2 The student academic performance distribution

\begin{tabular}{c|c|c|c|c}
\hline \multirow{2}{*}{ Year } & \multicolumn{4}{|c}{ Percentage (full score is 100) } \\
\cline { 2 - 5 } & Excellent(90 100) & $\operatorname{good}(80 \sim 89)$ & moderate(70 79) & poor(60 69) \\
\hline 2014 & $12.38 \%$ & $22.86 \%$ & $41.9 \%$ & $22.86 \%$ \\
\hline 2015 & $6.67 \%$ & $17.78 \%$ & $40 \%$ & $35.55 \%$ \\
\hline 2016 & $6.59 \%$ & $24.18 \%$ & $43.96 \%$ & $25.27 \%$ \\
\hline
\end{tabular}

In Table 2, we can see that the student academic performance distribution is very good, and all students pass this course. It has been proved practically that the proposed multidimensional interactive classroom teaching can achieved good teaching effect.

\section{CONCLUSION}

According to the actual situation of the "CCD principle and application, a short class hours and more content of course, in order to complete the teaching task in a limited 24 class hours, and enable students to fully understand and master the content of the course. Firstly, by combing and classifying the classroom content, the students can understand and master the basic content of the course from the overall and details. Secondly, by highlighting the key content points to the surface in the classroom, the students can really well to targeted responses and faster master the course-related content. Thirdly, by removing the old content reasonably and adding the relevant professional new technology in teaching, it not only enable students to broaden their horizons and learn from passive to active, but also stimulate student interest in learning and achieve a very good teaching effect. Moreover, the teaching efficiency of teachers and the independent thinking ability of students can be also improved by the combination of teaching and frontier science, scientific research project, living example. The scientific research project make students advance with the times and closely follow the pace of scientific research. The living example make students enhance the ability to understand things with knowledge, and improve the problem-solving ability in life. The author puts forward the reform of teaching contents and teaching methods. Through three years of teaching practice results show that through the reasonable selection and arrangement of teaching content, it has achieved good teaching results in the promotion of students learning ability and teachers teaching efficiency.

\section{REFERENCES}

[1] Chen Yuanzhi, "Reflections on teaching the course Photoelectric Detecting Technique," Journal of Guilin University of Electronic Technology 27 (5), 426-428 (2007).

[2] Zhang Ning, Xu Xiping, "Exploration and Practice of the Course Design of Optoelectronic Detection Technology," Education Teaching Forum 33, 223-224 (2012).

[3] Yan Junhong, Li Wentao, "Teaching Reform and Practice of Optoelectronic Detection Technology," China Electric Power Education 4, 56-57(2013).

[4] Zhang Baofu,Wu Chuanxin, Su Yang, Li Jianhua, "Teaching Practice on Photoelectic Technology in Small Class," Journal of EEE 32(1), 40-41(2013).

[5] Wang Yulin, "The Reform of Optoelectronic Detection Technology Course Based on Engineering Capability," 
Heilongjiang Science and Technology 28, 89(2016).

[6] Chu Fenghong, Hu Anduo, Xue Liang, Li Gaofang, Bian Zhenglan, Zhu Wu, "Exploration on the Teaching of Optoelectronic Detection Technology,” Journal of Higher Education 1, 52-53(2017).

[7] Zhou Zhengxian, Liu Chongchong, Zhou Rui, "Research on Optoelectronic Detection Technology Teaching," Education modernization 5,133-135(2016).

[8] Zhao Guangxing, Li Dan, Fang Ting, "Reform and Practice of Photoelectric Detection Technology Teaching Modes and Contents," Journal of Anhui University of Technology (Social Sciences Edition) 29(6),132-133 (2012). 